\title{
Potensi Asam Lemak pada Minyak Kelapa Murni dalam Menghambat Candida Albicans Secara In Vitro
}

\author{
Arina Novilla, Perdina Nursidika, Meyli Resmelia \\ Prodi DIII Analis Kesehatan STIKes Jenderal Achmad Yani
}

\begin{abstract}
Abstrak
Kandidiasis merupakan penyakit infeksi Candida baik primer maupun sekunder. Penyebab utama kandidiasis adalah Candida albicans (C. albicans). Pengobatan kandidiasis dilakukan dengan pemberian obat antijamur, terutama nistatin, amfoterisin-B dan azole, tetapi toksisitas dan resistensi obat ini menjadi masalah potensial. Diperlukan pemakaian obat lain yang lebih aman. Salah satunya adalah pemanfaatan bahan alami, yaitu minyak kelapa murni. Tujuan penelitian ini adalah mengetahui potensi asam lemak minyak kelapa murni dalam menghambat pertumbuhan C. albicans. Desain penelitian eksperimental. Penelitian menggunakan difusi Kirby Bauer untuk mendapatkan konsentrasi hambat minimum minyak kelapa murni dalam menghambat $C$. albicans. Penelitian dilakukan pada bulan September-Oktober 2010 di Laboratorium Kimia dan Mikrobiologi Sekolah Tinggi Ilmu Kesehatan Jenderal Achmad Yani Cimahi. Hasil menunjukkan asam lemak dalam fraksi n-heksan dan metanol hasil hidrolisis berpotensi dalam menghambat pertumbuhan C. albicans. Fraksi n-heksan konsentrasi minimal yang memberikan hambatan adalah $75 \%$ dengan diameter hambatan rata-rata sebesar 3,3 mm, sebanding dengan antibiotik nistatin 195 unit. Fraksi metanol memberikan hambatan dimulai pada konsentrasi 75\% dengan diameter hambatan rata-rata sebesar 4 mm, sebanding dengan antibiotik nistatin 195 unit. Hasil konsentrasi hambat minimum asam lemak masing-masing untuk fraksi metanol konsentrasi $25 \%$ dan fraksi $n$-heksan 100\%. Simpulan, asam lemak pada minyak kelapa murni dapat menghambat C. albicans. [MKB. 2016;48(4):200-4]
\end{abstract}

Kata kunci: Asam lemak, Candida albicans, in vitro, minyak kelapa murni

\section{Virgin Coconut Oil Fatty Acid Potential for Inhibiting the Growth of In Vitro Candida Albicans}

\begin{abstract}
Candidiasis includes both primary and secondary Candida infection.. The main cause of candidiasis is Candida albicans (C. albicans). Candidiasis is treated by antifungal drug treatment, specifically using nistatin, amphotericin-B, and azole. However, drug toxicity and resistance have become potential problems. Therefore, other methods are needed as a safer treatment. One of the natural resources which has antifungal property is virgin coconut oil. This was an experimental study to determine the potential of fatty acid in virgin coconut oil to inhibit $C$. albicans. Kirby Bauer Method was used to determine the minimum inhibition concentration. This study was performed in September-October 2010 at the Chemistry and Microbiology Laboratory of the School of Health Sciences, Jenderal Achmad Yani University Cimahi. The result showed the hydrolyzed fatty acid in n-hexane and methanol fractions had the potential to inhibit the growth of $C$. albicans. Minimum inhibitory concentration againstC. albicans was $75 \%$ with an average diameter of inhibiting zone of $3.3 \mathrm{~mm}$, which was equal to 195 units of nistatin. The methanol fraction inhibition on $C$. albicans started from $75 \%$ with an average diameter of $4 \mathrm{~mm}$ or equals to 195 units of nistatin. The minimum fungicidal concentration showed that $C$. albicanswas inhibitedby $25 \%$ methanol fraction and $100 \%$ n-hexane fraction. . In conclusion, fatty acid of virgin coconut oil has the ability to inhibit C. albicans. [MKB. 2016;48(4):200-4]
\end{abstract}

Key words: Candida albicans, fatty acids, in vitro, virgin coconut oil

Korespondensi: Arina Novilla, S. Pd., M. Si, Prodi DIII Analis Kesehatan STIKes Jenderal Achmad Yani, Jalan Terusan Jenderal Sudirman, Baros, Cimahi, Jawa Barat 40525, mobile 08122180284, e-mail arin.novilla@yahoo.co.id 


\section{Pendahuluan}

Minyak kelapa murni (virgin coconut oil/VCO) adalah produk olahan kelapa yang mulai banyak dikenal oleh masyarakat karena mengandung asam lemak tidak jenuh yang bermanfaat bagi kesehatan tubuh. Salah satu proses pembuatan minyak kelapa murni yang banyak digunakan ialah enzimatis (fermentasi). Proses pembuatan minyak kelapa murni dengan cara fermentasi tidak mengalami proses pemanasan dan tidak ada penambahan zat kimia sehingga minyak kelapa murni yang dihasilkan memiliki kualitas yang baik. ${ }^{1}$

Kandidiasis ialah merupakan penyakit yang disebabkan oleh infeksi Candida baik primer maupun sekunder terhadap penyakit lain yang telah ada. Penyebab utama kandidiasis adalah Candida albicans (C. albicans). Prevalensi kandidiasis saat ini banyak dihubungkan secara langsung dengan telah meluasnya penggunaan antibiotik. ${ }^{2,3}$ Penggunaan antibiotik yang meluas ini diasumsikan sebagai penyebab primer pertumbuhan Candida yang tidak terkontrol di dalam usus (Candida overgrowth) karena antibiotik ini tidak hanya membunuh bakteri penyebab infeksi, tetapi juga bisa membunuh bakteri flora normal yang berperan mengontrol pertumbuhan Candida tersebut. ${ }^{4}$ Pada umumnya pengobatan kandidiasis ini dilakukan dengan cara pemberian obat antijamur (kemoterapi), terutama nistatin, amfoterisin-B dan azole, tetapi toksisitas dan resistensi obat ini merupakan masalah potensial. ${ }^{5}$

Toksisitasyang ditimbulkan akibat pemakaian beberapa obat antijamur di antaranya kerusakan ginjal yang tidak dapat disembuhkan walaupun obat dihentikan, anemia hemolitik, gangguan fungsi alat pencernaan dan juga hati. ${ }^{6}$ Resistensi terhadap antijamur sebagai akibat perubahan enzim sehingga menyebabkan demetilasi yang mengganggu sintesis ergosterol jamur, produksi enzim yang berlebihan pada jamur, mutasi jalur metabolisme ergosterol yang mengakibatkan penumpukan sterol toksik, dan komponen sterol pada membran sel berkurang. ${ }^{7,8}$

Resistensi Candida terhadap berbagai macam obat antijamur (multidrug resistance) semakin berkembang. Oleh karena itu perlu metode lain sebagai upaya alternatif baik sebagai upaya pencegahan maupun pengobatan kandidiasis yang relatif lebih aman. Salah satunya dengan pemanfaatan bahan alami, yaitu minyak kelapa murni. Minyak kelapa murni memiliki kandungan asam lemak jenuh dan tidak jenuh yang memiliki banyak manfaat. ${ }^{9}$ Kandungan asam lemak rantai sedang (medium chain fatty acid) pada minyak kelapa murni dapat mematikan jamur C. albicans secara efektif sebagai alternatif penanganan infeksi jamur yang disebabkan oleh spesies candida yang resisten. ${ }^{10,11}$

\section{Metode}

Penelitian ini dilakukan menggunakan metode eksperimental, untuk menentukan konsentrasi hambat minimum minyak kelapa murni terhadap jamur C. albicans Penelitian ini terbagi atas empat tahapan kegiatan, yaitu pembuatan minyak kelapa murni mempergunakan Saccharomyces cereviceae, hidrolisis minyak kelapa murni, pengujian potensi asam lemak sebagai antijamur terhadap pertumbuhan C. albicans serta penentuan konsentrasi hambat minimum (KHM) asam lemak terhadap pertumbuhan $C$. albicans.

Hidrolisis minyak kelapa murni dilakukan untuk mendapatkan asam lemak. Dari hasil hidrolisis didapatkan 2 fraksi, yaitu fraksi n-heksan dan metanol. Hidrolisis minyak kelapa murni di dalam penelitian ini adalah dengan cara kimiawi. Dalam penelitian ini digunakan perbandingan mol trigliserida dan juga kalium hidroksida 1:5 karena waktu dan suhu reaksi yang dilakukan tidak pada kondisi optimum, yaitu pada suhu $80^{\circ} \mathrm{C}$ selama $1 \mathrm{jam}$. Setelah penambahan asam klorida terbentuk endapan putih di bawah cairan bening. Endapan putih ini merupakan kalium klorida, kemudian cairan bening diambil dan diekstraksi dengan $\mathrm{n}$-heksan sebanyak $50 \mathrm{~mL}^{12}$

Strain C. albicans diperoleh dari PT Biofarma dengan nomor ATCC 10231. Standar kekeruhan C. albicans adalah sebesar 0,5 Mc Farland dengan nilai optical density sebesar 0,1. Larutan uji dari fraksi metanol dan $n$-heksan dibuat berbagai variasi konsentrasi asam lemak minyak kelapa murni, yaitu dengan konsentrasi 100\%, 75\%, $50 \%$, dan $25 \%$. Pembuatan variasi konsentrasi antibiotik nistatin sebesar 100.000 unit; 50.000 unit; 25.000 unit; 12.500 unit; 6.250 unit; 3.125 unit; 1.563 unit; 782 unit; dan 391 unit.

Metode yang digunakan untuk uji aktivitas antijamur asam lemak pada minyak kelapa murni terhadap $C$. albicans adalah metode difusi Kirby Bauer. ${ }^{13}$ Pada cawan petri yang sudah berisi medium sabouraud dextrose agar (SDA) usapkan swab yang sudah dicelupkan ke dalam suspensi $C$. albicans yang mempunyai kekeruhan 0,5 Mac Farland, kemudian dibuat silinder pada agar tersebut, lalu diisi dengan larutan asam lemak sebanyak $20 \mu \mathrm{L}$. Selanjutnya, 
cawan petri dimasukkan ke dalam inkubator pada temperatur $37^{\circ} \mathrm{C}$ selama 24 jam. Pada pemeriksaan ini dilakukan kontrol negatif dan positif. Hasil uji dinyatakan secara kualitatif berdasarkan terdapat zona jernih di sekitar silinder. Pengukuran diameter dari setiap zona hambatan pertumbuhan bakteri yang dilakukan dengan jangka sorong/mistar. ${ }^{16}$ Penentuan KBM asam lemak minyak kelapa murni terhadap pertumbuhan $C$. albicans dilakukan dengan dua perlakuan, yaitu penanaman asam lemak minyak kelapa murni bersamaan dengan $C$. albicans dan penanaman $C$. albicans terlebih dahulu, lalu penambahan asam lemak minyak kelapa murni.

Penelitian ini dilakukan di Laboratorium Kimia dan Laboratorium Mikrobiologi Sekolah Tinggi Ilmu Kesehatan Jenderal Achmad Yani Cimahi pada bulan September-Oktober 2010.

\section{Hasil}

Pengujian aktivitas asam lemak diawali dengan hidrolisis minyak kelapa murni fraksi n-heksan dan metanol sehingga diperoleh asam lemak dari minyak kelapa murni. Tiap-tiap fraksi dibuat larutan emulsi menggunakan tween 80 hingga konsentrasi emulsi itu sebesar $10 \%$. Berdasarkan hasil uji antijamur fraksi n-heksan dan metanol terhadap C. albicans, kedua fraksi mampu menghambat $C$. albicans (Tabel 1). Pada fraksi n-heksan penghambatan dimulai pada konsentrasi $75 \%$ dengan diameter hambatan rata-rata sebesar 3,3 mm dan pada konsentrasi $100 \%$ sebesar $14 \mathrm{~mm}$. Zona hambatan pada fraksi metanol terjadi mulai konsentrasi $75 \%$

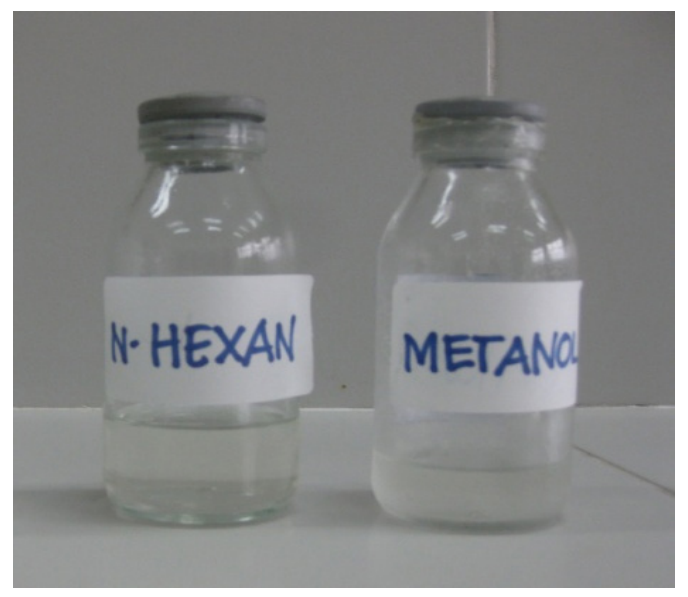

Gambar 1 Hasil Hidrolisis Minyak Kelapa Murni Fraksi N-Heksan dan Metanol

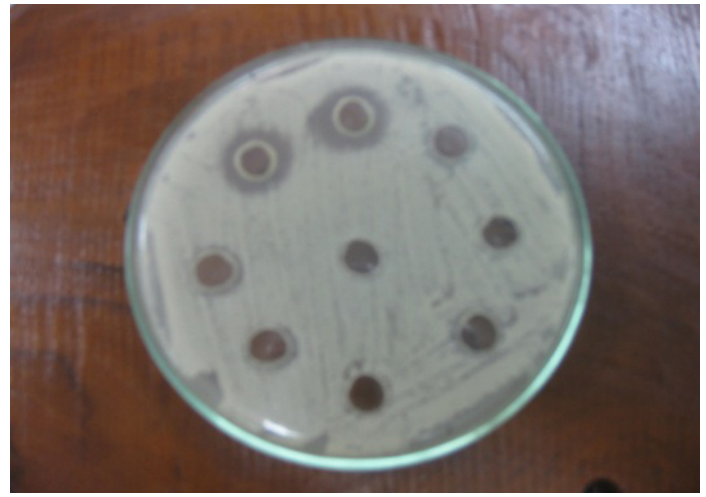

Gambar 2 Zona Hambatan Asam Lemak Minyak Kelapa Murni terhadap C. albicans

sebesar $4 \mathrm{~mm}$, sedangkan pada konsentrasi $100 \%$ sebesar $6 \mathrm{~mm}$.

Penelitian ini menguji aktivitas antimikrob denganantibiotiknistatindengan berbagaivariasi konsentrasi. Berdasarkan atas hasil penelitian menunjukkan bahwa pada konsentrasi fraksi metanol $75 \%$ memiliki potensi daya hambat sebanding dengan konsentrasi nistatin 391 unit, sedangkan fraksi n-heksan mempunyai potensi daya hambat sebanding dengan konsentrasi nistatin 195 unit, yaitu sebesar 3 mm, sedangkan pada konsentrasi fraksi metanol $100 \%$ potensi daya hambatnya sebanding dengan konsentrasi nistatin 1.563 unit, yaitu sebesar $6 \mathrm{~mm}$. Berbeda halnya dengan fraksi n-heksan pada konsentrasi $100 \%$ nya potensi daya hambatnya sebanding dengan konsentrasi nistatin $>100.000$ unit

Hasil penentuan KBM didapatkan bahwa C. albicans yang ditumbuhkan bersama-sama asam lemak yang terdapat dalam fraksi metanol ternyata dapat menghambat $C$. albicans sampai

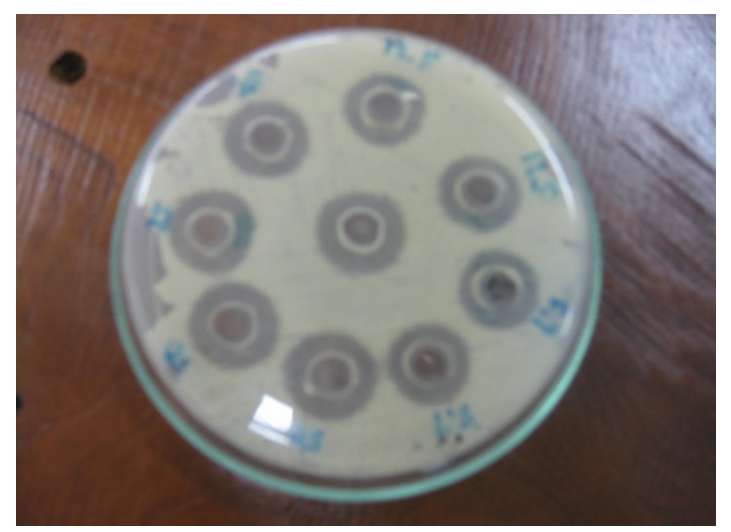

Gambar 3 Zona Hambatan Nistatin terhadap C. albicans 
Tabel 1 Hasil Uji Antijamur Berbagai

Konsentrasi Asam Lemak Minyak Kelapa Murni terhadap Pertumbuhan C. albicans

\begin{tabular}{|c|c|c|c|c|}
\hline \multirow{2}{*}{ Fraksi } & \multicolumn{4}{|c|}{$\begin{array}{l}\text { Rata-rata Diameter Hambatan } \\
(\mathrm{mm})\end{array}$} \\
\hline & $25 \%$ & $50 \%$ & $75 \%$ & $100 \%$ \\
\hline N-heksana & - & - & 3,3 & 14 \\
\hline Metanol & - & - & 4 & 6 \\
\hline
\end{tabular}

konsentrasi terendah, yaitu 25\%. Hasil ini menunjukkan bahwa secara in vitro jika dalam keadaan terinfeksi, asam lemak fraksi metanol dapat menghambat C. albicans mulai konsentrasi $25 \%$, sedangkan pada fraksi n-heksan dapat menghambat $C$. albicans hanya pada konsentrasi $100 \%$.

Namun, jika C. albicans ditumbuhkan terlebih dahulu maka asam lemak yang terkandung dalam fraksi metanol dapat menghambat $C$. albicans sampai konsentrasi terendah, yaitu 1,56\%. Hal ini dapat disimpulkan bahwa secara in vitro jika sudah terkena infeksi $C$. albicans maka asam lemak dalam minyak kelapa murni dapat berfungsi sebagai antijamur yang dapat membunuh C. albicans. Pada asam lemak pada fraksi n-heksan tidak dapat bersifat sebagai antijamur atau membunuh $C$. albicans apabila $C$. albicans ditumbuhkan terlebih dahulu.

\section{Tabel 2 Hasil Uji Antimikroba Berbagai Konsentrasi Nistatin terhadap Pertumbuhan C. albicans Metode Kirby Bauer}

\begin{tabular}{cc}
\hline Konsentrasi (unit) & $\begin{array}{c}\text { Rata-rata } \\
\text { Diameter Hambatan } \\
\text { (mm) }\end{array}$ \\
\hline 98 & 2 \\
195 & 3 \\
391 & 4 \\
782 & 5 \\
1.563 & 6 \\
3.125 & 7 \\
6.250 & 8 \\
12.500 & 9 \\
25.000 & 10 \\
50.000 & 11 \\
100.000 & 12 \\
\hline
\end{tabular}

\section{Pembahasan}

Asam lemak rantai sedang pada minyak kelapa yaitu asam laurat yang merupakan asam lemak dominan yang terkandung pada minyak kelapa memiliki khasiat sebagai antiinflamasi, pengatur sistem imun, antivirus, antijamur, antibakteri, dan antiprotozoa. ${ }^{14}$ Asam lemak tidak jenuh dapat menghambat aktivitas dari mitokondria $C$. albicans dan juga $C$. dubliniensis, sehingga dapat menghambat pertumbuhan biomasa biofilm jamur. Asam lemak tak jenuh berpengaruh pula pada morfologi biofilm spesies Candida. Hal ini disebabkan oleh meningkatnya stres oksidatif akibat asam lemak tidak jenuh terikat pada komponen lipid sel. ${ }^{15}$

Terdapat zona hambatan pada penentuan aktivitas antimikrob salah satunya disebabkan zat aktif dalam asam lemak hasil hidrolisis dalam fraksi n-heksan dan metanol. Asam lemak diduga sebagai zat aktif untuk menghambat pertumbuhan C. albicans. Mekanisme kerja asam lemak sebagai antijamur dengan cara merusak sitoplasma dan juga merusak plasma membran sehingga sel menciut. Mikroorganisme akan mudah dibunuh oleh asam lemak rantai sedang dengan cara menghancurkan membran lemaknya. Membran mikroorganisme memiliki kemiripan struktur dengan oleh asam lemak rantai sedang, tetapi senyawa oleh asam lemak rantai sedang lebih kecil sehingga mudah melemahkan cairan membran terdekat menjadi membran terurai. Membran menjadi terbuka, mengeluarkan isinya, dan membunuh bakteri. Sel darah putih dengan cepat menyapu dan membuang puing sel tersebut. Asam lemak rantai sedang dapat membunuh organisme tanpa menyebabkan bahaya pada jaringan manusia. ${ }^{16}$

Pada penelitian ini kami belum melakukan pemurnian asam lemak yang dihasilkan dari cara pemisahan secara hidrolisis. Berdasarkan atas hasil penelitian menunjukkan asam lemak dalam fraksi n-heksan dan metanol hasil hidrolisis berpotensi menghambat pertumbuhan C. albicans. Asam lemak dapat membunuh $C$. albicans pada saat ditanam bersamaan pada media, keadaan ini menunjukkan asam lemak minyak kelapa murni dapat digunakan sebagai antijamur pada keadaan awal infeksi. Hasil dari penanaman C. albicans terlebih dahulu kemudian ditambah asam lemak menunjukkan hanya asam lemak di dalam fraksi metanol yang dapat menghambat C. albicans. Hasil ini sejalan dengan penelitian Winarsi dkk. ${ }^{17}$ yang menyatakan bahwa asam lemak dalam minyak kelapa murni mampu meningkatkan imunitas 
pada penderita kandidiasis. Hal ini menunjukkan dengan pemberian minyak kelapa murni pada awal infeksi yang dapat menghambat penyakit menjadi lebih parah. Simpulan, asam lemak dalam minyak kelapa murni dapat menghambat C. albicans.

\section{Ucapan Terima Kasih}

Ucapan terima kasih kepada Direktorat Jenderal Pendidikan Tinggi Departemen Pendidikan dan Kebudayaan atas bantuan dana penelitian melalui program Penelitian Dosen Muda tahun 2009.

\section{Daftar Pustaka}

1. Neela S, Prasad NBL. Induced fermentative production of virgin coconut oil. As J Food Ag-Ind. 2012;5(5):355-63.

2. Hatta TH, Amin S, Adriani A. Resistance of antifungal for Candida SPP. Indonesian J Dermatol Veneral. 2012:1(1);42-9.

3. Pfaller MA. Antifungal drug resistance: mechanisms, epidemiology, and consequences for treatment. Am Med. 2012; 125:S3-13.

4. Spampinato C,Leonardi D.Candida infections, causes, targets, and resistance mechanisms: traditional and alternative antifungal agents. Biomed Res Int. 2013;2013:204237.

5. LaFleur MD. Candida albicans biofilms, heterogeneity and antifungal drug tolerance. To Myc J. 2011;5(1):21-8.

6. Worth LJ, Blyth CC, Booth DL, Kong DC, Marriott D, Cassumbhoy M, dkk. Optimizing antifungal drug dosing and monitoring to avoid toxicity and improve outcomes in patients with haematological disorders. Int Med J. 2008;38(6B):521-37.

7. Chițescu CL, Nicolau A. Another point of view on side effects of antifungal compounds used in veterinary medicine. Medicamentul Veterinar. 2011;5(1):68-71.

8. Kanafani ZA, Perfect JR. Resistance to antifungal agents: mechanisms and clinical impact. Clin Infect Dis. 2008:46(1);120-8.

9. Arif T, Bhosale JD, Kumar N, .Mandal TK, Bendre RS, Lavekar GS, dkk. Natural productsantifungal agents derived from plants. J Asian Nat Prod Res. 2009;11(7):621-38.

10. Novarianto $H$, Tulalo M. Kandungan asam laurat pada berbagai varietas kelapa sebagai bahan baku VCO. J Littri. 2007; 13(1):28-33.

11. Ogbou DO, Oni AA, Daini OA, Oloko AP. In vitro antimicrobial properties of coconut oil on Candida species in Ibadan, Nigeria. J Med Food. 2007;10(2):384-7.

12. Dimzon IKD, Valde MF, Santos JER, Garrovillas MJM, Dejarme HM, Remollo JMW, dkk. Physico-chemical and microbiological parameters in the deterioration of virgin coconut oil. Phil J Sci. 2011;140(1):89-103.

13. Khan F, Baqai R. In vitro antifungal sensitivity of fluconazole, clotrimazole and nystatin against vaginal candidiasis in females of childbearing age. J Ayub Med Coll Abbottabad. 2010;22(4):197-200.

14. Gupta A, Malav A, Singh A, Gupta MK, Khinchi MP, Sharma N, dkk. Coconut oil: the healthiest oil on earth. IJPSR. 2010;1(6):19-26.

15. Thibane VS, Kock JLF, Ells R, Wyk WJV, Pohl CH. Effect of marine polyunsaturated fatty acids on biofilm formation of Candida albicans and Candida dubliniensis. Mar Drugs. 2010;8(10):2597-604.

16. Fife BND, Kabara JJ, Dayrit C. The health benefits of virgin coconut oil. MPI Publication [Online Article] 2006 [diunduh 17 Juli 2013]. Tersedia dari: http://www.agriculture.org.fj.

17. Winarsi H, Hernayanti, Purwanto A. Virgin coconut oil (VCO) enriched with $\mathrm{Zn}$ as immunostimulator for vaginal candidiasis patient. Hayati J Biosci. 2008;15(4):135-9. 